\title{
Study of variance, heritability and genetic advance for various yield contributing and quality traits in spring wheat (Triticum aestivum $\mathbf{L}$. .)
}

\section{Harshwardhan, Anil Kumar, Amarjeet Kumar*and Birendra Prasad}

Department of Genetics and Plant Breeding, College of Agriculture, G. B. Pant University of Agriculture and Technology, Pantnagar-263145 (Uttarakhand), INDIA

*Corresponding author. E-mail: amarjeetagriculture@gmail.com

Received: January 22, 2016; Revised received: July 23, 2016; Accepted: October 12, 2016

\begin{abstract}
An experiment was conducted to study the coefficient of variance, heritability and genetic advance for different traits in spring wheat. The investigation comprised of 7 lines of wheat and their 21 crosses in half diallel fashion was carried out in RBD with three replications. Data were recorded for days to $75 \%$ heading, days to maturity, plant height, number of productive tillers per plant, spike length, number of spikelets per spike, number of grains per spike, grain weight per spike, 1000-grain weight, biological yield per plant, harvest index, grain yield per plant, protein content and sedimentation value. The mean squares of the analysis of variance revealed significant and highly significant differences among genotypes for characters studied. Both PCV and GCV $(21.8 \%$ and $21.3 \%)$ were highest for biological yield per plant followed by grain yield per plant $(20.9 \%)$ and harvest index $(19.7 \%)$ respectively. Whereas, ECV was maximum (15.2\%) for grain yield per plant followed by harvest index (12.2\%) and lowest value was recorded for days to $75 \%$ heading $(0.85 \%)$. Days to $75 \%$ heading was highly heritable $(90.94 \%)$ trait followed by plant height $(87.23 \%)$ while least heritability $(17.73 \%)$ was noticed for number of grain per spike. The highest genetic advance shown by the biological yield per plant $(48.33 \mathrm{~g})$ followed by grain yield per plant $(19.75 \mathrm{~g})$, however, the greatest genetic value percent mean 43.084 for the days to maturity and minimum (2.10) for spike length. Hence, these statistical parameters might be given top priority to strengthen the successful breeding program.
\end{abstract}

Keywords: Genetic advance, Heritability, Quality, Spring wheat, Variance, Yield

\section{INTRODUCTION}

Wheat (Triticum aestivum L.) is the most important cereal of the world which belongs to poaceae family and world's leading cereal grain and most important food crop, occupying commanding position in Indian Agriculture, which occupies $28 \%$ area under cereals and contributing $33 \%$ of the total food grain production in the country. Wheat offers a great wealth of material for genetical studies due to its wide ecological distribution and enormous variation encountered for various morphological and physiological characters (Rangare et al., 2010).

The ultimate aim of any plant breeding programme is to develop cultivars with high potential and consistent performance over diverse environments. Hybridization is an important source for creation of variation (Kumar et al., 2015a). The study of genetic variability is the pre-requisite for any crop improvement programme. Success in recombination breeding depend on suitable exploitation of genotypes as parent of obtaining high heterotic crosses and transgressive sergeants or the presence of genetic variability in base population is essential (Allarad, 1960). The efficiency of breeding program increases by careful choice of parents and populations capable of producing progeny with desirable trait combinations (Kumar et al., 2015b; Cristina et al., 2002). Before embarking on any improvement program, genetic information regarding the inheritance of quantitative characters, particularly the nature and choice of the most effective breeding procedures depends to a large extent on knowledge of the genetic systems controlling the characters to be selected (Yadav et al., 2013). Primarily, biological variation presented in the plant population is of three types, viz., phenotypic, genotypic and environmental. The estimate of heritability serves as a useful guide to the breeder (Kumar et al., 2015c). The breeder is able to appreciate the proportion of variation is due to genotypic (broad sense heritability) or additive (narrow sense heritability) effect that is the heritable portion of variation in the first case and the portion of genetic variation that is pure line in the later case. Selection efficiency for a plant trait depends on extent of its heritability and genetic variation (Falconer et al., 1996). The existing genetic variability shows that the population has high genetic potential for improvement of the characters by selection programmes. Heritability is a technique used by the plant breeders for effectively isolating the amount of genetic variation from the total phenotypic variation. The aims of the present investigation were to the estimation of coefficient of varance, 
heritability and genetic advance for different traits in spring wheat.

\section{MATERIALS AND METHODS}

The present research was carried out at Norman E. Borlaug Crop Research Centre of Govind Ballabh Pant University of Agriculture and Technology, Pantnagar. India. The material for the present study was developed during Rabi 2012-13 and the progenies were evaluated in the next Rabi season of 2013-14.Seven genetical diverse wheat varieties i.e. WH 542, HD 2967, PBW 621, UP 2526, QLD 40, UP 2672 and UP 2425 was crossed in diallel mating design excluding reciprocals. The parents and F1 seeds of 21 crosses along with 2 checks i.e. DPW 621-50, UP 2526 were planted in a randomized complete block design with 3 replications. Parents and F1 were grown in two rows plot of 1 meter length in each replication during Rabi 2013-14. The plant to plant distance was maintained at $10 \mathrm{~cm}$ and row to row as $20 \mathrm{~cm}$. The material was planted in mid-November, 2013-14 under high fertility timely sown conditions. Wheat varieties were crossed with each other in a half-diallel mating design, resulting in 21 hybrid combinations, equal to $\mathrm{p}(\mathrm{p}-1) / 2$, where $p$ is the number of parents used. The parents, F1 hybrids and checks were grown in a randomized block design in three replications. Each plot in a replication comprised of parents and F1's having double row of $1 \mathrm{~m}$ length. The rows were spaced in $20 \mathrm{~cm}$ apart and plant-toplant distance was maintained at $10 \mathrm{~cm}$ by dibbling. $\mathrm{Ob}-$ servations were recorded on the whole plot basis for days to $75 \%$ heading and days to maturity, whereas the character like plant height, number of effective tillers per plant, spike length, number of spikelet per spike, number of grains per spike, grain weight per spike, 1000 grain weight, grain yield per plant, biological yield and harvest index were taken over five randomly selected competitive plants from each plot. Harvest index was calculated in percentage by the proportion of total grain yield in comparison to biological yield .For estimation of quality parameter in terms of protein content and sedimentation value samples were analyzed with the help of NIT based Whole Grain Analyzer (Infratech 1241 Grain Analyzer). Analysis of variance was done for partitioning the total variation into variation due to treatments and replications according to procedure given by Panse and Sukhatme (1967). In the present investigation three types of coefficient of variations were estimated viz., phenotypic coefficient of variation (PCV), genotypic coefficient of variation (GCV) and error/environmental coefficient of variation (ECV). It was calculated by the formula given by Burton and Devane (1953). The estimates of genetic advance were obtained by the formula given by Johnson $e t$ al. (1955).

\section{RESULTS AND DISCUSSION}

The general mean, range, coefficient of variation along with genotypic, phenotypic and environmental coeffi-

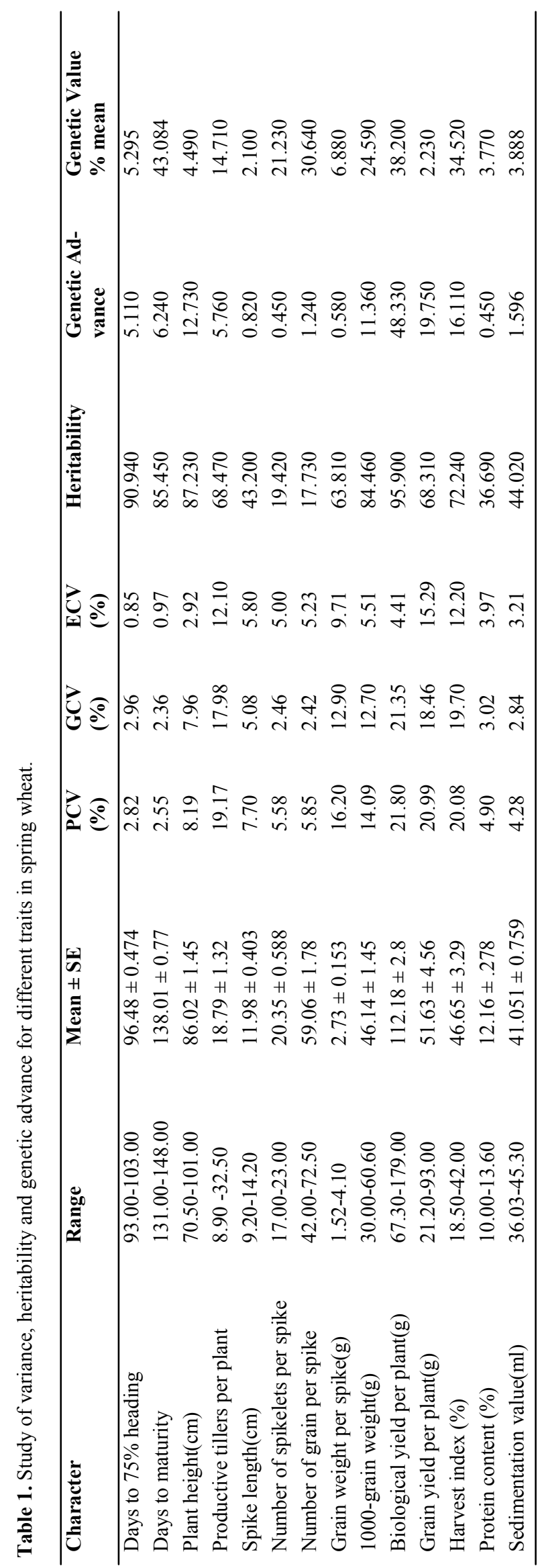


cient of variation, heritability and genetic advance are presented in table1. The estimated values of phenotypic coefficient of variation were higher than genotypic coefficient of variation for all the characters studied except for days to $75 \%$ heading and more than environmental coefficient of variation for all the characters studied. Biological yield (21.80\%) exhibited highest phenotypic coefficient of variation followed by grain yield per plant $(20.99 \%)$, harvest index (20.08\%), productive tillers per plant $(19.17 \%)$, grain weight per spike (16.20\%), 1000 grain weight $(14.09 \%)$, plant height $(8.19 \%)$, spike length $(7.70 \%)$, number of grains per spike $(5.85 \%)$, number of spikelets per spike $(5.58 \%)$, protein content $(4.90 \%)$, sedimentation value $(4.28 \%)$, days to $75 \%$ heading $(2.82 \%)$. The lowest phenotypic coefficient of variation was observed for days to maturity (2.55). Biological yield $(21.35 \%)$ exhibited highest genotypic coefficient of variation followed by harvest index (19.70\%), grain yield per plant (18.46), productive tillers per plant $(17.98 \%)$, grain weight per spike $(12.90 \%), 1000$ grain weight $(12.70 \%)$, plant height $(7.96 \%)$, spike length $(5.08 \%)$, protein content $(3.02 \%)$, days to $75 \%$ heading $(2.96 \%)$, sedimentation value $(2.84 \%)$, number of spikelets per spike $(2.46 \%)$. The lowest genotypic coefficient of variation was observed for days to maturity $(2.36 \%)$. Highest value for phenotypic coefficient of variation was observed for biological yield followed by grain yield per plant and harvest index. However, biological yield exhibited highest genotypic coefficient of variability followed by harvest index and grain yield per plant. Four varieties/lines of wheat and their crosses were evaluated by Eid (2011) to estimate heritability and genetic advance for yield traits. Low, medium and high heritability was found in different yield traits under study. High heritability accompanied by high genetic advance was observed for spike length and 1000 grain weight. Low heritability coupled with low genetic advance was for plant height and number of grains per spike and Prasad et al. (2005) in sorghum. The range of environmental coefficient of variation was observed from 0.85 for days to $75 \%$ heading to $15.29 \%$ for grain yield per plant. Environmental coefficient of variability was highest for grain yield per plant followed by harvest index and productive tillers per plant. These results indicated that, the environment had an important role in the expression of these characters and the diverse genotypes can provide materials for a sound breeding programme. These results are in harmony with those obtained by Kumar et al. (2015d); and Hassan et al. ( 2013); they estimated heritability, correlation coefficient and variance components while Zaazaa et al. (2012) also studied genetical analysis of some quantitative traits in wheat. However, Prasad et al. (2012) reported genetic variation in Perilla germplasm. The efficacy of the selections of both yield and the yield components depend on the genetic variation and percentage of heritability (Prasad, 2014). Heritability estimates were higher and is necessary to identify the components that create the phenotypical difference in order to calculate the genetic variability and heritability based on that variation. In the present investigation broad sense heritability was estimated for various traits. The heritability estimate varied from $17.73 \%$ (number of grain per spike) to $95.90 \%$ (biological yield per plant). High values of heritability were also found for days to heading (90.94), plant height (87.23), and days to maturity (85.45). Such type of findings have also been reported by Kumar et al. (2014) who appraised heritability estimates that revealed characters like biological yield per plant exhibited highest heritability followed by test weight and flag leaf length. Genetic advance as \% of mean for all the characters is presented in table 1 . This ranged from $2.107 \%$ (spike length) to 43.08 (days to maturity). Biological yield (38.06) and harvest index (34.52) also expressed high genetic advance. Kumar et al. (2014) also evaluated thirty genotypes of bread wheat and reported high genetic advance for plant height, biological yield per plant and moderate for harvest index, test weight and low genetic advance was observed for flag leaf width, days to $50 \%$ flowering, spike length and flag leaf length. The present findings of this investigation exhibited high values of heritability for biological yield per plant and high genetic advance for days to maturity. High heritability and high genetic advance indicates that preponderance of additive gene effect, therefore, characters can be better exploited through selection.

\section{Conclusion}

On the basis of present investigation, it was concluded that the differences among genotypes were highly significant for all the characters. The high extent of variability is suitable for generation of transgressive segregants in a hybridization programme. Since, biological yield (21.35), grain yield per plant(18.46), harvest index(19.70), productive tillers per plant (17.98), grain weight per spike (12.90) and 1000 grain weight (12.70) possessed a high genotypic coefficient of variation, therefore, these may be considered as main selection criteria.

\section{REFERENCES}

Allard, R.W. (1960). Principle of plant breeding, John Wiley \& Sons, Inc., New York, pp. 270-274

Burton, G.W. and DeVane. (1953). Estimating heritability in Tall Fescue from replicated clonal material. Agronomy J., 45:475-481

Cristina de, F.M., Santos dos, J.B., Nunes Sousa de, G.H. and Ramalho, M.A.P. (2002). Choice of common bean parents based on combining ability estimates. Gen. Mol. Biol., 25(2): 179-183

Eid, H. M. (2011). Estimation of heritability and genetic advance of yield traits in wheat (Triticum aestivum L.) under drought condition. Int. Journal of Genetics and Mol., 11 (2): 115-120 
Falconer, D.S., Mackay, T.F.C. and Trudy, F.C. (1996) Introduction to quantitative genetics. 4 . Ed. Harlow, UK, Longman Group, 464 p. ISBN 978-0-582-24302-6

Hassan, M.S., El-Said, R.A.R. and Abd-El-Haleem, S.H.M. (2013). Estimation of heritability and variance components for some quantitative traits in bread wheat (Triticum aestivum L.). World Applied Sciences J., 27 (8): 944-949

Johnson, H.W., Robinnson, H.F. and Comstock, R.K. (1955). Genotypic and phenotypic correlation in soybean and their implication in selection. Agronomy j., 47: 447483

Kumar, A., Harshwardhan, Kumar, A. and Prasad, B. (2015a). Heterotic performance of diallel F1 crosses over parents for yield and its contributing traits in bread wheat (Triticum aestivum L.). Journal of Hill Agriculture, 6 (1):58-61

Kumar, A., Harshwardhan, Kumar,A. and Prasad,B. (2015b). Combining ability and gene interaction study for yield, its attributing traits and quality in common wheat. $J$. Appl. \& Nat. Sci., 7 (2): 927 - 934

Kumar, A., Prasad, B. and Kumar,A. (2015c). Study of variance components of combining ability for yield, its attributing traits in common bread wheat. Elixir Agriculture, 81: 31425-31426

Kumar, A., Harshwardhan, Kumar,A. and Prasad,B.(2015d). Estimation of correlation coefficient for yield and quality parameters of bread wheat under tarai region of pantnagar. Annals of Plant and Soil Research, 17 (special issue): 224-228

Kumar, N., Markar, S. and Kumar, V. (2014). Studies on heritability and genetic advance estimates in timely sown bread wheat (Triticum aestivum L.) Bioscience Discovery, 5 (1):64-69

Kumar, R.., Bharti, S., Kumar, A. and Nagar, S. S. (2014). Genetic variability, heritability and genetic advance in bread wheat.Environment and Ecology, 31 (v): 405-407

Panse, C.G. and Sukhatme, P.V. (1967). Statistical method for agricultural workers. 2nd edu. pp/381,I.C.A.R.,New Delhi.

Prasad, B., Bahuguna, A., Shukla, D.K. (2012). Genotypic variation studies of Perilla (Perilla frutescens L.) germplasm under North-West Himalayan agri-silvi system. Environment and Ecology, 30 (4): 1235-1237

Prasad, B., Shukla, P.S., Singh, R. (2005). Effect of staggered planting of male parent on seed yield and quality of forage sorghum hybrid, PCH-106 .Seed Res., 33 (2): 213-214

Prasad, B. (2014). Heterotic vigour studies in forage sorghum hybrid by multiple criteria. Journal of Hill Agric., 5 (2): 182-185

Rangare, N.R., Krupakar, A., Kumar, A. and Singh, S. (2010). Character association and component analysis in wheat (Triticum aestivum). Electronic $J$. of Plant Breeding, 1(3): 231-238

Yadav, A., Kumar, A., Roy, C. and Jaiswal, J.P. (2013). Correlation and path- coefficient analysis for grain yield, its components and quality traits in bread wheat. Pantnagar Journal of Research, 11 (3): 337-340

Zaazaa, E. I., Hager, M.A. and El-Hashash, E.F. (2012). Genetical analysis of some quantitative traits in wheat using six parameters genetic model. American Eurasian J. Agric. and Environ. Sci., 12(4): 456-462 